
\title{
28 Research Square \\ When Does Early Palliative Care Influence Aggressive Care At The End of Life?
}

Mellar P Davis ( $\square$ mdavis2@geisinger.edu )

Geisinger Medical Center https://orcid.org/0000-0002-7903-3993

\section{Erin vanenkevort}

Geisinger Medical Center

Alexander Elder

Geisinger Medical Center

Amanda Young

Geisinger Medical Center

Irina Correa Ordonez

Geisinger Medical Center

Mark Wojtowicz

Geisinger Medical Center

Halle Ellison

Geisinger Medical Center

Carlos Fernandez

Geisinger Medical Center

Zankhana Mehta

Geisinger Medical Center

Bertrand Behm

Geisinger Medical Center

Glen Digwood

Geisinger Medical Center

Rajiv Panikkar

Geisinger Medical Center

\section{Research Article}

Keywords: Aggressive, Care, End-of-Life, Palliative, Advance Directives

Posted Date: September 1st, 2021

DOI: https://doi.org/10.21203/rs.3.rs-806612/v1 
License: (c) (i) This work is licensed under a Creative Commons Attribution 4.0 International License. Read Full License

Version of Record: A version of this preprint was published at Supportive Care in Cancer on March 15th, 2022. See the published version at https://doi.org/10.1007/s00520-022-06954-2. 


\section{Abstract \\ Background}

Early palliative care improves patient quality of life and influences cancer care. The time frame of early has not been established. Eight quality measures reflect aggressive care at the end of life. We retrospectively reviewed patients who died with cancer between January 1, 2018 through December 31, 2019 , and compared the timing of palliative care consultation, advance directives (AD), and home palliative care with aggressive care at the end of life (ACEOL).

\section{Methods}

Patients without ACEOL indicators were compared to patients with one or more than one indicator of ACEOL. The proportion of patients who received palliative care, completed AD, and the timing of palliative care and $A D$ (less than 30 days, 60-90 days, and greater than 90 days prior to death) was compared for patients who had ACEOL versus those who did not. Chi-square analysis was used for categorical data, one-way ANOVA for continuous variables, and odds ratio (OR) with confidence intervals ( $\mathrm{Cl})$ was reported as a measure of effect size. A p-value $</=0.05$ was considered significant.

\section{Results}

1727 patients died, $46 \%$ were female, and the mean age was 69 (SD 11.91). $71 \%$ had a palliative care consult, $26 \%$ completed AD, $888(51.4 \%)$ had at least one indicator of ACEOL. AD completed at any time reduced ACEOL (OR $0.80,95 \% \mathrm{Cl} 0.64-0.99$ ). Palliative care was associated with a greater risk of ACEOL at 30 days (OR 5.32, 95\% $\mathrm{Cl} 3.94-7.18$ ) and between 30 and 90 days (OR 1.39,95\% $\mathrm{Cl} 1.07-1.80$ ), but dramatically reduced $A C E O L$ at $>90$ days $(\mathrm{OR} 0.46,95 \% \mathrm{Cl} 0.38-0.57)$. The most common indicator of ACEOL was new chemotherapy within 30 days of death, in 571 of 888 (64\%) of patients experiencing ACEOL.

\section{Discussion}

$A D$ reduce $A C E O L$ and often reflect goals of care and end-of-life discussions in the transition of care away from tumor directed therapy. Palliative care paradoxically in our experience is associated with greater ACEOL in the first 90 days since consultation occurs late in the course of illness and the focus is on crisis management in patients who are frequently utilizing the health care system. If palliative care consultation occurs greater than 90 days before death, there is the opportunity for both aggressive symptom management and end of life discussions which may influence aggressive care at the end of life. 


\section{Conclusions}

An initial palliative care consult greater than 90 days before death and ADs completed at any time during the disease trajectory significantly impacts care at the end of life. Both should become quality metrics for good cancer care.

\section{Introduction}

Aggressive cancer care is considered poor quality care which includes chemotherapy at the end of life, multiple emergency department visits, rehospitalizations, intensive care unit (ICU) admissions and hospital mortality. A retrospective review of the National Cancer Institute Surveillance, Epidemiology, and End Results (SEER) database dating from 1993 to 1996 identified characteristics of aggressive care at the end of life (ACEOL) (Table 1). ${ }^{1,2}$ These seven indicators, and hospitalization for 14 days within the last month of life, ${ }^{1}$ were identified as poor outcomes to cancer care.

\section{Table 1 Indicators of Aggressive Care at the End of Life}

New chemotherapy initiated within 30 days of death

Chemotherapy administered within 14 days of death

Greater than 1 hospitalization within 30 days of death

Greater than 2 emergency room visits within 30 days of death

An intensive care admission within 30 days of death

Death within the hospital

No hospice admission or hospice services of less than 3 days in duration

One third of patients are reported to have at least one indicator of ACEOL. ${ }^{3}$ Several studies have found that early palliative care, reduces ACEOL. ${ }^{4,5}$ Intrinsic to an early palliative care referral is a prognostic understanding of the patient's cancer. ${ }^{6,7}$ Definitions and timeframe of early palliative care are not established. ${ }^{3}$ Timely palliative care has been defined as more than 30 days before death, greater than eight weeks before death, and within eight weeks of diagnosis of metastatic disease. ${ }^{3,4,8,9}$ Benefits to palliative care are reported to occur regardless of the trajectory of advanced cancer. ${ }^{10-12}$ Paradoxically, palliative care has been associated with ACEOL if consultations are late in the disease course or patients are transferred to an inpatient palliative care unit. ${ }^{3}$

The multiple studies find that the time to palliative referral for the most part is late; the time between consultation and death ranges from five to fifty-four days. ${ }^{13-15}$ In a recently published systematic review 
and meta-analysis, the median time between palliative care consultation and death was 18.9 days (IQR $0.1){ }^{16}$

The purpose of this retrospective study was to primarily determine the the proportion of patients who underwent ACEOL. We wanted to understand the influence of a comprehensive palliative care program which consists of inpatient and outpatient services as well as an inpatient unit on ACEOL and the influence and timing of ADs on ACEOL. Our hypothesis was that palliative care service consultations first instituted greater than 30 days prior to death and preferably greater than 90 days before death and completed ADs would be associated with reduced ACEOL.

\section{Methods}

This is a retrospective cohort study of patients ages 18-99 diagnosed with cancer, followed within the Geisinger Health System, who died in the years 2018 and 2019. Data were collected from the electronic medical record within the dates of $01 / 01 / 2018$ to $12 / 31 / 2019$. The study inclusion criteria included patients ages 18-99 with a diagnosis of cancer who received chemotherapy and died in 2018-2019. All patients had available to them inpatient and outpatient palliative care services but was dependent on the referring oncologist or primary care physician. The Geisinger Health Plan also has a community-based palliative care program for members; patients could receive Geisinger at Home Palliative services were included in the study.

Exclusion Criteria included patients who died within 30 days of the diagnosis of cancer. The primary outcome was the proportion of patients having indicator(s) of ACEOL as outlined and included the metric of 14 days of hospitalization in the last 30 days of life. Data for hospice referrals and duration of hospice services could not be obtained, therefore this indicator was excluded. The other outcome of interest was the completion and timing of ADs.

Demographic and clinical characteristics were summarized and compared across aggressive care groups defined as receiving no indicators of ACEOL compared to one or more indicators. Demographic and clinical data included sex, age at death, organ site of primary disease, Charlson Comorbidity Index (CCI), Geisinger Health Plan insurance, and clinical visit with hematology or oncology within 12 months before death. Frequencies and percentages were reported for categorical variables; for continuous variables mean and standard deviations were reported. To assess differences among patients who had one or more indicators of ACEOL to those who did not have any, Chi-square analyses were conducted on dichotomous and categorical data (e.g., sex) and one-way analysis of variance (ANOVA) tests were conducted for continuous outcome variables (e.g., age at death). Odds ratios from the Chi-square analysis were used as a measure of effect size. $95 \%$ confidence intervals and associated p-values are also reported. A p-value less than or equal to 0.05 indicated statistical significance. Statistical analyses were conducted using SOFTWARE VERSION***.

This study was approved by the Geisinger Institutional Review Board. 


\section{Results}

Of the 1,727eligible patients, $790(46 \%)$ were female; the average age was 69 (SD = 11.9). Thirty-five percent $(n=611)$ had Geisinger Health Plan, $27 \%$ had lung cancer $(n=473)$, the majority $(88 \%)$ of patients had hematology or oncology visits within 12 months prior to death. The average $\mathrm{CCl}$ score was seven $(S D=3.7)$.

There were no significant differences in sex or $\mathrm{CCl}$ scores between those receiving palliative care services and those not. There was a significant difference between patients who had no indicators of aggressive care at end of life, one indicator of aggressive care, and more than one indicator of aggressive care on type of cancer and age at death. Patients who received no aggressive care were older, and those with more than one indicator were younger than those who only had one indicator of aggressive care (Table 2). 
Table 2

Demographic Characteristics by Aggressive Care Indicators

\begin{tabular}{|c|c|c|c|c|c|}
\hline & Total & $\begin{array}{l}\text { No } \\
\text { aggressive } \\
\text { care }\end{array}$ & $\begin{array}{l}\text { One indicator of } \\
\text { aggressive care }\end{array}$ & $\begin{array}{l}\text { More than one indicator } \\
\text { of aggressive care }\end{array}$ & $\begin{array}{l}\text { P- } \\
\text { Value }\end{array}$ \\
\hline & $\begin{array}{l}(\mathrm{N}= \\
1727)\end{array}$ & $(\mathrm{N}=839)$ & $(N=314)$ & $(N=574)$ & \\
\hline Female, N (\%) & $\begin{array}{l}790 \\
(45.7 \%)\end{array}$ & $\begin{array}{l}387 \\
(46.1 \%)\end{array}$ & 141 (44.9\%) & $262(45.6 \%)$ & 0.932 \\
\hline $\begin{array}{l}\text { Age at Death, } \\
\text { Mean (SD) }\end{array}$ & $\begin{array}{l}69.0 \\
(11.91)\end{array}$ & $\begin{array}{l}70.5 \\
(12.01)\end{array}$ & 68.9 (11.82) & $66.8(11.48)$ & $<.0001$ \\
\hline Disease, N (\%) & & & & & 0.024 \\
\hline $\begin{array}{l}\text { Bladder / } \\
\text { Kidney }\end{array}$ & $\begin{array}{l}72 \\
(4.2 \%)\end{array}$ & $32(3.8 \%)$ & $16(5.1 \%)$ & $24(4.2 \%)$ & \\
\hline Breast & $\begin{array}{l}113 \\
(6.5 \%)\end{array}$ & $58(6.9 \%)$ & $18(5.7 \%)$ & $37(6.4 \%)$ & \\
\hline Colon / Rectum & $\begin{array}{l}137 \\
(7.9 \%)\end{array}$ & 75 (8.9\%) & $24(7.6 \%)$ & 38 (6.6\%) & \\
\hline Esophageal & $\begin{array}{l}63 \\
(3.6 \%)\end{array}$ & $27(3.2 \%)$ & $15(4.8 \%)$ & $21(3.7 \%)$ & \\
\hline $\begin{array}{l}\text { Female } \\
\text { Reproductive }\end{array}$ & $\begin{array}{l}99 \\
(5.7 \%)\end{array}$ & 48 (5.7\%) & $22(7.0 \%)$ & $29(5.1 \%)$ & \\
\hline Head \& Neck & $\begin{array}{l}76 \\
(4.4 \%)\end{array}$ & 48 (5.7\%) & $12(3.8 \%)$ & $16(2.8 \%)$ & \\
\hline Liver \& Bile Duct & $\begin{array}{l}28 \\
(1.6 \%)\end{array}$ & $18(2.1 \%)$ & $1(0.3 \%)$ & $9(1.6 \%)$ & \\
\hline Lung & $\begin{array}{l}473 \\
(27.4 \%)\end{array}$ & $\begin{array}{l}220 \\
(26.2 \%)\end{array}$ & $82(26.1 \%)$ & $171(29.8 \%)$ & \\
\hline Lymphoma & $\begin{array}{l}89 \\
(5.2 \%)\end{array}$ & $39(4.6 \%)$ & $16(5.1 \%)$ & $34(5.9 \%)$ & \\
\hline $\begin{array}{l}\text { Melanoma and } \\
\text { other Skin }\end{array}$ & $\begin{array}{l}43 \\
(2.5 \%)\end{array}$ & $19(2.3 \%)$ & $7(2.2 \%)$ & $17(3.0 \%)$ & \\
\hline Pancreas & $\begin{array}{l}112 \\
(6.5 \%)\end{array}$ & $56(6.7 \%)$ & $26(8.3 \%)$ & $30(5.2 \%)$ & \\
\hline Prostate & $\begin{array}{l}95 \\
(5.5 \%)\end{array}$ & $61(7.3 \%)$ & $15(4.8 \%)$ & $19(3.3 \%)$ & \\
\hline Thyroid & $\begin{array}{l}10 \\
(0.6 \%)\end{array}$ & $5(0.6 \%)$ & $1(0.3 \%)$ & $4(0.7 \%)$ & \\
\hline
\end{tabular}




\begin{tabular}{|llllll|}
\hline & Total & $\begin{array}{l}\text { No } \\
\text { aggressive } \\
\text { care }\end{array}$ & $\begin{array}{l}\text { One indicator of } \\
\text { aggressive care }\end{array}$ & $\begin{array}{l}\text { More than one indicator } \\
\text { of aggressive care }\end{array}$ & $\begin{array}{l}\text { P- } \\
\text { Value }\end{array}$ \\
\hline Other & $\begin{array}{l}317 \\
(18.4 \%)\end{array}$ & $\begin{array}{l}133 \\
(15.9 \%)\end{array}$ & $59(18.8 \%)$ & $125(21.8 \%)$ & 0.339 \\
\hline $\begin{array}{l}\text { Geisinger Health } \\
\text { Plan, N (\%) }\end{array}$ & $\begin{array}{l}611 \\
(35.4 \%)\end{array}$ & $\begin{array}{l}303 \\
(36.1 \%)\end{array}$ & $118(37.6 \%)$ & $190(33.1 \%)$ & 0.864 \\
\hline $\begin{array}{l}\text { HemOnc a year } \\
\text { before, N (\%) }\end{array}$ & $\begin{array}{l}1528 \\
(88.5 \%)\end{array}$ & $\begin{array}{l}741 \\
(88.3 \%)\end{array}$ & $276(87.9 \%)$ & $511(89.0 \%)$ & 0.454 \\
\hline $\begin{array}{l}\text { Charlson Score, } \\
\text { Mean (SD) }\end{array}$ & $\begin{array}{l}7.1 \\
(3.75)\end{array}$ & $7.2(3.91)$ & $7.0(3.55)$ & $7.0(3.63)$ & \\
\hline
\end{tabular}

Twenty-six percent had completed ADs documented. Patients who had no indicators had a greater percentage of documented ADs compared to patients who had ACEOL, but the difference was not statistically significant (Table 3). Ads were categorized as completed within 30 days, between 30 and 90 days, and more than 90 days before death. There were no significant group differences. Completed ADs reduced chemotherapy utilization within 30 days of death and ICU admissions (Table 4).

Table 3

Advanced Directives by Aggressive Care Indicators

\begin{tabular}{|c|c|c|c|c|c|}
\hline & Total & $\begin{array}{l}\text { Aggressive } \\
\text { Care }\end{array}$ & $\begin{array}{l}\text { No Aggressive } \\
\text { Care }\end{array}$ & \multirow[t]{2}{*}{$\begin{array}{l}\text { P- } \\
\text { value }^{1}\end{array}$} & \multirow[t]{2}{*}{$\begin{array}{l}\text { Odds Ratio (OR) } \\
(95 \% \mathrm{Cl})\end{array}$} \\
\hline & $\begin{array}{l}(N= \\
1727)\end{array}$ & $(N=888)$ & $(\mathrm{N}=839)$ & & \\
\hline Any Advanced Directive & $\begin{array}{l}443 \\
(25.7 \%)\end{array}$ & $\begin{array}{l}209 \\
(23.5 \%)\end{array}$ & $234(27.9 \%)$ & 0.038 & $0.80(0.64,0.99$ \\
\hline $\begin{array}{l}\text { Advanced Directives } \\
30-90 \text { days }\end{array}$ & $4(0.2 \%)$ & $4(0.5 \%)$ & $0(0.0 \%)$ & 0.052 & - \\
\hline $\begin{array}{l}\text { Advanced Directives > } 90 \\
\text { days }\end{array}$ & $\begin{array}{l}439 \\
(25.4 \%)\end{array}$ & $\begin{array}{l}205 \\
(23.1 \%)\end{array}$ & $234(27.9 \%)$ & 0.022 & $0.78(0.62,0.96)$ \\
\hline
\end{tabular}

${ }^{1}$ Chi-Square p-value 
Table 4

The Influence of Advance Directives on Aggressive Care at the End of Life

\begin{tabular}{|c|c|c|c|}
\hline Indicator & $\begin{array}{l}\text { No Advanced } \\
\text { Directives } \\
(n=1284)\end{array}$ & $\begin{array}{l}\text { Advanced } \\
\text { Directives } \\
(n=443)\end{array}$ & $\begin{array}{l}\text { P- } \\
\text { value }^{1}\end{array}$ \\
\hline $\begin{array}{l}\text { New chemotherapy initiated within } 30 \text { days of } \\
\text { death }\end{array}$ & $448(34.8 \%)$ & $123(27.8 \%)$ & 0.006 \\
\hline Chemotherapy given within 2 weeks of death & $204(15.9 \%)$ & $59(13.3 \%)$ & 0.194 \\
\hline An ICU admission within 30 days of death & $54(4.2 \%)$ & $9(2.0 \%)$ & 0.035 \\
\hline Greater than 1 ED visit within 30 days of death & $205(16.0 \%)$ & $67(15.1 \%)$ & 0.675 \\
\hline $\begin{array}{l}\text { Greater than } 1 \text { hospitalization visit within } 30 \\
\text { days of death }\end{array}$ & $163(12.7 \%)$ & $59(13.3 \%)$ & 0.735 \\
\hline Death within the hospital & $251(19.5 \%)$ & $84(19.0 \%)$ & 0.788 \\
\hline $\begin{array}{l}\text { Admission greater than } 14 \text { days in last } 30 \text { days } \\
\text { before death }\end{array}$ & $107(8.3 \%)$ & $43(9.7 \%)$ & 0.376 \\
\hline
\end{tabular}

Seventy-one percent had a palliative care consultation. This frequency differed among the groups. Specifically, $78 \%$ of patients who had more than one indicator of aggressive care, $70 \%$ of those who had one indicator, and $66 \%$ of those who did not receive ACEOL had palliative care services (Table 5 ). The odds of having a palliative care consultation for patients with one or more than one indicator of aggressive care was $1.20(95 \% \mathrm{Cl}: 0.90,1.59)$ and $1.78(95 \% \mathrm{Cl}: 1.40,2.27)$ fold greater than those with no indicators. This pattern was consistent with a large proportion of palliative care consultations within 30 days of death and palliative care consultations 30-90 days before death. However, those who had no indicators of aggressive care (45\%), and one indicator of aggressive care (33\%) were more likely to receive a palliative care consultation greater than 90 days before death compared to those who had more than one indicator of aggressive care (25\%). The odds of a palliative care consult being initiated more than 90 days before death for those with one or more than one aggressive care indicator was 0.59 (95\% Cl: $0.45,0.78)$ and 0.40 (95\% Cl: $0.32,0.51)$ times the odds of those with no aggressive care indicators, respectively. 
Table 5

Palliative Care Services by Aggressive Care Indicators

\begin{tabular}{|c|c|c|c|c|c|}
\hline & Total & $\begin{array}{l}\text { Aggressive } \\
\text { Care }\end{array}$ & $\begin{array}{l}\text { No Aggressive } \\
\text { Care }\end{array}$ & \multirow[t]{2}{*}{$\begin{array}{l}\text { P- } \\
\text { value }^{1}\end{array}$} & \multirow[t]{2}{*}{$\begin{array}{l}\text { Odds Ratio (OR) } \\
(95 \% \mathrm{Cl})\end{array}$} \\
\hline & $\begin{array}{l}(\mathrm{N}= \\
1727)\end{array}$ & $(N=888)$ & $(N=839)$ & & \\
\hline $\begin{array}{l}\text { Any Palliative Care } \\
\text { Services }\end{array}$ & $\begin{array}{l}1221 \\
(70.7 \%)\end{array}$ & $\begin{array}{l}666 \\
(75.0 \%)\end{array}$ & $555(66.2 \%)$ & $<.0001$ & $1.53(1.25,1.89)$ \\
\hline $\begin{array}{l}\text { Palliative Consult within } \\
30 \text { days }\end{array}$ & $\begin{array}{l}318 \\
(18.4 \%)\end{array}$ & $\begin{array}{l}258 \\
(29.1 \%)\end{array}$ & $60(7.2 \%)$ & $<.0001$ & $5.32(3.94,7.18)$ \\
\hline $\begin{array}{l}\text { Palliative Consult 30- } \\
90 \text { days }\end{array}$ & $\begin{array}{l}278 \\
(16.1 \%)\end{array}$ & $\begin{array}{l}162 \\
(18.2 \%)\end{array}$ & $116(13.8 \%)$ & 0.012 & $1.39(1.07,1.80)$ \\
\hline $\begin{array}{l}\text { Palliative Consult }>90 \\
\text { days }\end{array}$ & $\begin{array}{l}625 \\
(36.2 \%)\end{array}$ & $\begin{array}{l}246 \\
(27.7 \%)\end{array}$ & $379(45.2 \%)$ & $<.0001$ & $0.46(0.38,0.57)$ \\
\hline
\end{tabular}

Seven percent received Geisinger at Home Palliative services which did not differ among groups. Geisinger at Home Palliative services within 30 days of death, 30-90 days before death, and more than 90 days before death also did not differ among groups.

Supportive services included completed Ads, palliative care services, and Geisinger at Home Palliative services. There was a significant difference in the number of supportive services across groups.

Specifically, fewer patients who had more than one indicator of ACEOL received no supportive services compared to those with one indicator or no indicators. A greater percentage of patients who had more than one indicator received one supportive service compared to those who had one or no indicators. Patients with one indicator of aggressive care had the greatest percentage of receiving two supportive services, and those with no indicators had the greatest percentage of receiving all three supportive services. The odds of having one or more supportive services for those with one or more than one indicator of aggressive care was $0.98(95 \% \mathrm{Cl}: 0.76,1.22)$ and $0.88(95 \% \mathrm{Cl}: 0.72,1.08)$ relative to no aggressive care indicators, respectively (Table 6). To determine the impact of palliative care services, Geisinger at Home Palliative and palliative care inpatient and outpatient consultations were combined to create a "palliative care service" indicator. Table 6 demonstrates the differences across groups; no supportive services, palliative care services only, palliative care services and ADs, or only ADs. There is a significant difference among groups $(p=0.0003)$ where the odds of supportive services for patients with one or more than one indicator of ACEOL of $0.84(95 \% \mathrm{Cl}: 0.66,1.07)$ and $0.61(95 \% \mathrm{Cl}: 0.50,0.75)$ fold less than those with no indicators, respectively (Table 6). We also examined the influence of any supportive services that included palliative care services compared to those who only completed ADs or no supportive services (Supplementary Table 1). There was a significant group difference $(p=$ 0.0001).The odds of any supportive services that included palliative care for those with one or more than 
one indicator was $1.18(95 \% \mathrm{Cl}: 0.88,1.57)$ and $1.71(95 \% \mathrm{Cl}: 1.33,2.19)$ fold the odds of those with no indicators, respectively. 
Table 6

Supportive services by Indicators of Aggressive Care.

\begin{tabular}{|c|c|c|c|c|c|}
\hline & Total & $\begin{array}{l}\text { Aggressive } \\
\text { Care }\end{array}$ & $\begin{array}{l}\text { No } \\
\text { Aggressive } \\
\text { Care }\end{array}$ & $\begin{array}{l}\text { P- } \\
\text { value }^{1}\end{array}$ & $\begin{array}{l}\text { Odds Ratio } \\
\text { (OR) }(95 \% \mathrm{Cl})\end{array}$ \\
\hline & $\begin{array}{l}(\mathrm{N}= \\
1727)\end{array}$ & $(\mathrm{N}=888)$ & $(N=839)$ & & \\
\hline $\begin{array}{l}\text { Number of Supportive } \\
\text { Services }\end{array}$ & & & & 0.052 & $\begin{array}{l}0.91(0.76 \\
1.10)\end{array}$ \\
\hline No Supportive Services & $\begin{array}{l}370 \\
(21.4 \%)\end{array}$ & $\begin{array}{l}173 \\
(19.5 \%)\end{array}$ & $197(23.5 \%)$ & & \\
\hline 1 supportive service & $\begin{array}{l}956 \\
(55.4 \%)\end{array}$ & $\begin{array}{l}511 \\
(57.5 \%)\end{array}$ & $445(53.0 \%)$ & & \\
\hline 2 supportive services & $\begin{array}{l}366 \\
(21.2 \%)\end{array}$ & $\begin{array}{l}191 \\
(21.5 \%)\end{array}$ & $175(20.9 \%)$ & & \\
\hline 3 supportive services & $\begin{array}{l}35 \\
(2.0 \%)\end{array}$ & $13(1.5 \%)$ & $22(2.6 \%)$ & & \\
\hline $\begin{array}{l}\text { Palliative Care vs. Advanced } \\
\text { Directives }\end{array}$ & & & & 0.0002 & $\begin{array}{l}0.69(0.57 \\
0.82)\end{array}$ \\
\hline no supportive services & $\begin{array}{l}370 \\
(21.4 \%)\end{array}$ & $\begin{array}{l}173 \\
(19.5 \%)\end{array}$ & $197(23.5 \%)$ & & \\
\hline advanced directives only & $\begin{array}{l}98 \\
(5.7 \%)\end{array}$ & $34(3.8 \%)$ & $64(7.6 \%)$ & & \\
\hline palliative care only & $\begin{array}{l}914 \\
(52.9 \%)\end{array}$ & $\begin{array}{l}506 \\
(57.0 \%)\end{array}$ & $408(48.6 \%)$ & & \\
\hline $\begin{array}{l}\text { palliative care and advanced } \\
\text { directives }\end{array}$ & $\begin{array}{l}345 \\
(20.0 \%)\end{array}$ & $\begin{array}{l}175 \\
(19.7 \%)\end{array}$ & $170(20.3 \%)$ & & \\
\hline $\begin{array}{l}\text { Any Palliative Care vs. } \\
\text { Advanced Directives }\end{array}$ & & & & 0.0001 & $\begin{array}{l}0.66(0.53 \\
0.81)\end{array}$ \\
\hline no supportive services & $\begin{array}{l}370 \\
(21.4 \%)\end{array}$ & $\begin{array}{l}173 \\
(19.5 \%)\end{array}$ & $197(23.5 \%)$ & & \\
\hline advanced directives only & $\begin{array}{l}98 \\
(5.7 \%)\end{array}$ & $34(3.8 \%)$ & $64(7.6 \%)$ & & \\
\hline palliative care services & $\begin{array}{l}1259 \\
(72.9 \%)\end{array}$ & $\begin{array}{l}681 \\
(76.7 \%)\end{array}$ & $578(68.9 \%)$ & & \\
\hline $\begin{array}{l}\text { Palliative Care vs. No } \\
\text { Palliative Care }\end{array}$ & & & & 0.0003 & $\begin{array}{l}1.49(1.20 \\
1.84)\end{array}$ \\
\hline no palliative care services & $\begin{array}{l}468 \\
(27.1 \%)\end{array}$ & $\begin{array}{l}207 \\
(23.3 \%)\end{array}$ & $261(31.1 \%)$ & & \\
\hline
\end{tabular}




\begin{tabular}{|c|c|c|c|c|c|}
\hline & Total & $\begin{array}{l}\text { Aggressive } \\
\text { Care }\end{array}$ & $\begin{array}{l}\text { No } \\
\text { Aggressive } \\
\text { Care }\end{array}$ & $\begin{array}{l}\text { P- } \\
\text { value }^{1}\end{array}$ & $\begin{array}{l}\text { Odds Ratio } \\
\text { (OR) }(95 \% \mathrm{Cl})\end{array}$ \\
\hline & $\begin{array}{l}(\mathrm{N}= \\
1727)\end{array}$ & $(N=888)$ & $(N=839)$ & & \\
\hline palliative care services & $\begin{array}{l}1259 \\
(72.9 \%)\end{array}$ & $\begin{array}{l}681 \\
(76.7 \%)\end{array}$ & $578(68.9 \%)$ & & \\
\hline
\end{tabular}

Three hundred fourteen of 888(35.4\%) patients had one ACEOL indicator and 574 (64.6\%) had more than one indicator ( Supplementary Table 1,2). The most common indicator was chemotherapy within the last 30 days of life, which occurred in 571 of 888 (64.3\%) patients. Younger patients were more likely to receive chemotherapy within the last 30 days of life. Neither sex nor $\mathrm{CCl}$ influenced chemotherapy at 30 or 15 days before death. (Supplementary Table 3). Approximately $20 \%$ of patients died in the hospital. The least common indicator was ICU admissions, which occurred in 63 of 888 patients (7\%). Compared with no palliative care services, palliative care initiated at greater than 90 days reduced new chemotherapy within 30 days of death and chemotherapy administered within 15 days of death ( Supplementary Table 4). Palliative care services initiated greater than 90 days before death was associated with decreased emergency department utilization and hospital admission compared with palliative care initiated at less than 90 days but not less than those who were not seen by palliative care. However, patients who had a palliative consult greater than 90 days before death had significantly less chemotherapy initiated within 30 days of death and less chemotherapy continued within 2 weeks of death then those who had not had a palliative care consult (Supplementary Table 4).

\section{Discussion}

Half of patients who died in the years 2018 and 2018 had at least one indicator of ACEOL; only 1/3 were seen greater than 90 days prior to death. A quarter of the patients had completed ADs, most were completed $>90$ days prior to death. Documented ADs reduced ACEOL by reducing the number of patients receiving chemotherapy at the end-of-life and ICU admission. ADs completed at any point in time did reduce ACEOL though few though were completed < 90 days before death. Palliative care consultation > 90 days before death reduced ACEOL by reducing chemotherapy given in the last month of life.

Completion of $A D s$ reduces aggressive care at the end of life. This requires discussions about patient values and an understanding of prognosis. End-of life-discussions are more likely to have occurred for those with an AD. Prognostic awareness occurs in $49 \%$ of patients with an advanced illness but this varied based upon country. ${ }^{17}$ Lack of prognostic awareness and inaccurate prognostication are associated with ACEOL. ${ }^{6,18-21}$ Oncologists tend to be optimistic in their prognostication. ${ }^{22}$ Hence, they may put off $A D$ discussions until late in the course of cancer. " Hoping for the best but planning for the worst" may be an important way of approaching patients about personal values in light of an incurable 
illness with completion ADs in a timely fashion even if a timeframe of survival is not discussed or does not want to be discussed by patients. ${ }^{23}$

In a retrospective review of patients with advanced cancer, completion of ADs greater than 90 days before death reduced rehospitalization within 90 days of death (odds ratio $0.21: 905 \% \mathrm{Cl} 0.12$ to 0.37 ). ${ }^{24} \mathrm{~A}$ second retrospective study of women with advanced ovarian cancer found that end-of-life discussions greater than 30 days before death reduced chemotherapy in the last 14 days of life, reduced hospitalizations within 30 days of death and increased the number of hospice days. ${ }^{25}$ In a large cohort study of lung and colon cancer patients, $39 \%$ of end-of-life discussions took place in the last 30 days of death. For the subset in which discussions took place greater than 30 days before death there was a reduction in all indicators of ACEOL except ICU admissions. ${ }^{6}$ The Cancer Care Outcomes Research and Surveillance Consortium study found that the median time between end-of-life discussions and death was 33 days suggesting that for many there is a lost opportunity to discuss choices at the end-oflife. ${ }^{26} \mathrm{Also}$, a significant proportion of patients do not engage or do not want to engage in end of life discussions and a significant proportion of end of life discussions occur under crisis conditions in the last 30 days of life. Less than half of physicians know their patients' preferences for end-of-life care including resuscitation. ${ }^{6,27-30}$ Completion of ADs prior to hospitalization is preferred. Most patients prior to admission have decision-making capacity but half of advanced cancer patients lose decision making capacity in hospital. If then a surrogate becomes the decision-maker in the place of patient, there is a greater risk that $\mathrm{ACEOL}$ will take place. ${ }^{31}$ Decisions regarding resuscitation prior to hospitalization reduces the number resuscitations that occur after hospitalization, reduces intensive care unit length of stay and hospital mortality. ${ }^{32}$

Our findings are consistent with two systematic reviews. ${ }^{33,34}$. Both reviews demonstrated that end-of-life discussions and advanced care planning reduces ACEOL and healthcare expenditures. Reduction in intensive care utilization (odds ratio $0.26-0.68$ ) and chemotherapy (odds ratio $0.41-0.57$ ) were two major benefits.

Many patients have end- of-life discussions but not recorded in the medical record. One study found that only $48 \%$ were recorded in the medical record and $23 \%$ were known only through interviewing the surrogate decision-maker. ${ }^{6}$ It is possible that more patients had Ads in our study but were not documented in the medical record

Seventy percent of patients who died of were cancer were seen by our palliative care service but only $1 / 3$ were seen greater than 90 days prior to death. Palliative care consultations within 90 days of death were associated with increased ACEOL ; only those patients initially seen greater than 90 days prior to death had a significant reduction in ACEOL.

Half of patients dying of cancer in our study had at least one indicator of aggressive care and is consistent with a retrospective study of women with gynecological cancers. In this study $41 \%$ had at least one indicator. ${ }^{35}$ Younger patients are more likely to receive chemotherapy at the end of life. Comorbidities 
and gender did not play a role in ACEOL in our study Comorbidity has been published as a risk factor for ACEOL. ${ }^{36}$ Gender in in several other studies was found to be different with males undergoing more aggressive care and women received less ACEOL. 2,3,10 This may reflect differences in referral and individual oncologist's practice style.

A small study of patients with cervical cancer found that the median time frame for palliative care referral before death was 2.3 months with $34 \%$ referred within the last month of life. ${ }^{37}$ A systematic review found the average time from palliative care consultation to death was 18.9 days. ${ }^{16}$.

In a large review of patients with advanced gastrointestinal cancers $(n=34,630)$ the median time from palliative care to death was 76 days and $46 \%$ had palliative care services initiated greater than 90 days prior to death. Twelve percent had services initiated within 7 days of dying. ${ }^{12} \mathrm{~A}$ retrospective review of patients with pancreatic cancer found the median survival time from palliative consultation was 75 days, only $52 \%$ had palliative care consultations. ${ }^{10}$

We uniquely found that palliative care consultations within 90 days of death was associated with more ACEOL which differs from previously published studies. ${ }^{10,12}$. Few studies have looked at the time-frame of palliative care and ACEOL. This likely reflects crisis intervention at the end-of-life in patients who have had multiple hospitalizations, emergency room visits and may be in the ICU in which primary services feel a goals of care discussion is needed or a transition to hospice or comfort care in needed. Patients are often seen by our service for the first time after several emergency department visits or readmission after receiving chemotherapy or for reasons of cancer. Our experience is not unique ${ }^{3}$.. A retrospective study of patients with pancreatic cancer found that late palliative care consultations defined as occurring less than 90 days prior to death was associated with an $18 \%$ greater use of the emergency department, a $12.5 \%$ greater number of hospitalizations and increased chemotherapy in the last 30 days of life. ${ }^{38}$

We observed a robust reduction in ACEOL when a palliative care consultation took place greater than 90 days before death. Though there is no universal definition of "early palliative care", we believe that $>90$ days before death has practical utility. Others have defined "early palliative care" as consultations $>90$ days to death to within 8 weeks of the diagnosis of metastatic disease. ${ }^{3,4,11}$ Two studies suggest that the number of contacts may be an important factor to early palliative care. ${ }^{10,39}$. Increased contacts between the patient and palliative services reduce ACEOL and with $>90$ days of time, the number of contacts are likely to increase which allows for the development of trusting relationship, time for symptom management and end-of-life discussions. Two studies suggest that the number of contacts are an important factor in early palliative care. ${ }^{10,39}$ A systematic referral of patients with incurable cancer facilitates early referral and is more likely reduce ACEOL. ${ }^{9}$

We found that $64 \%$ of patients who experience ACEOL receive new chemotherapy within 1 month of death and nearly $30 \%$ continue chemotherapy within 2 weeks of death. Frequency of other indicators is consistent with the literature. ${ }^{40} \mathrm{~A}$ retrospective study of patients who received chemotherapy within 3 
months of death found that $52 \%$ were treated with chemotherapy in the last month of life and $29 \%$ in the last 2 weeks of life. ${ }^{41}$ Another study, contrary to ours, found that though hospital deaths were more frequent than ours (47.7\%), chemotherapy within 14 days of death was only $12.9 \%, 9.1 \%$ had new chemotherapy started within 30 days of death. ${ }^{42}$ Maltoni and colleagues found that early palliative care defined as palliative care within 8 weeks of diagnosis reduced chemotherapy from $27.8-18.7 \%$ in the last month of life. ${ }^{9}$ A second study demonstrated a reduction in late chemotherapy from $24.5-16.7 \%$ with early palliative care defined as palliative care greater than 90 days before death. ${ }^{38}$ Multiple other studies have demonstrated the same though not consistently. ${ }^{10-12,37}$

. Even though the prognosis may be the same regardless of age, younger patients are more likely to receive anti-cancer therapy within the last month of life. A Finnish study found that $33 \%$ of patients less than 50 years old received chemotherapy in the last month of life versus $10 \%$ of those 80 years or older. ${ }^{43}$

The use of chemotherapy within 14 days of death has increased over 2 decades. ${ }^{1}$ One reason, is that there are more treatment options. There can be unrealistic expectations of chemotherapy or fear of "doing nothing" on the part of the patient and physician. ${ }^{21} \mathrm{~A}$

This study has several weaknesses. We defined advanced cancer patients by their diagnosis and by receiving chemotherapy. Some patients may have received adjuvant chemotherapy and died from other causes rather than their cancer. The association of ACEOL with palliative care $<90$ days may reflect a referral pattern of sicker patients though the $\mathrm{CCI}$ did not differ between groups. We were unable to obtain hospice referral data which is one of the indicators of ACEOL and hence some patients in the "nonaggressive care" group may actually have been referred to hospice later or not at all and would have been part of the group experiencing ACEOL. The use of palliative care services early in the course of advanced cancer and completed ADs may reflect a patient's value which emphasizes quality of life and less ACEOL. Finally, there could be unmeasured confounders that we did not include that could have influenced the results. This was a single institution study and so may not be generalizable.

\section{Conclusions}

Half of patients who died with cancer experience at least one indicator of ACEOL.. Palliative care consultations greater than 90 days before death significantly reduces ACEOL as does completion of ADs. The most frequent indicator of aggressive care is new chemotherapy within 30 days of death. In our experience early palliative care should be defined as palliative care consultations occurring more than 90 days before death. Early palliative care and completion of ADs should be quality metrics within cancer programs.

\section{Declarations}

Funding: None 
Conflicts of interest/Competing interests: None

Availability of data and material: NA

Code availability: NA

Authors' contributions:

Manuscript development and writing; Mellar Davis, Erin A. Vanenkevort, Alexander Elder, Amanda Young, Irina D. Correa Ordonez, Mark J Wojtowicz, Halle Ellison, Carlos Fernandez, Zankhana Mehta, Bertrand Behm, Glen Digwood, Rajiv Panikkar

Ethics approval: NA

Consent to participate: NA

Consent for publication: NA

\section{References}

1. Earle CC, Landrum MB, Souza JM, Neville BA, Weeks JC, Ayanian JZ (2008) Aggressiveness of cancer care near the end of life: is it a quality-of-care issue? J Clin Oncol 26(23):3860-3866

2. Earle CC, Neville BA, Landrum MB, Ayanian JZ, Block SD, Weeks JC (2004) Trends in the aggressiveness of cancer care near the end of life. J Clin Oncol 22(2):315-321

3. Hui D, Kim SH, Roquemore J, Dev R, Chisholm G, Bruera E (2014) Impact of timing and setting of palliative care referral on quality of end-of-life care in cancer patients. Cancer 120(11):1743-1749

4. Temel JS, Greer JA, Muzikansky A et al (2010) Early palliative care for patients with metastatic nonsmall-cell lung cancer. N Engl J Med 363(8):733-742

5. Zimmermann C, Swami N, Krzyzanowska M et al (2014) Early palliative care for patients with advanced cancer: a cluster-randomised controlled trial. Lancet 383(9930):1721-1730

6. Mack JW, Cronin A, Keating NL et al (2012) Associations between end-of-life discussion characteristics and care received near death: a prospective cohort study. J Clin Oncol 30(35):43874395

7. Yoong J, Park ER, Greer JA et al (2013) Early palliative care in advanced lung cancer: a qualitative study. JAMA Intern Med 173(4):283-290

8. Chow E, Abdolell M, Panzarella T et al (2008) Predictive model for survival in patients with advanced cancer. J Clin Oncol 26(36):5863-5869

9. Maltoni M, Scarpi E, Dall'Agata M et al (2016) Systematic versus on-demand early palliative care: results from a multicentre, randomised clinical trial. Eur J Cancer 65:61-68

10. Jang RW, Krzyzanowska MK, Zimmermann C, Taback N, Alibhai SM. Palliative care and the aggressiveness of end-of-life care in patients with advanced pancreatic cancer. J Natl Cancer Inst. 
2015;107(3)

11. Lees C, Weerasinghe S, Lamond N, Younis T, Ramjeesingh R (2019) Palliative care consultation and aggressive care at end of life in unresectable pancreatic cancer. Curr Oncol 26(1):28-36

12. Merchant SJ, Brogly SB, Goldie C et al (2018) Palliative Care is Associated with Reduced Aggressive End-of-Life Care in Patients with Gastrointestinal Cancer. Ann Surg Oncol 25(6):1478-1487

13. Good PD, Cavenagh J, Ravenscroft PJ (2004) Survival after enrollment in an Australian palliative care program. J Pain Symptom Manage 27(4):310-315

14. Bennett MI, Ziegler L, Allsop M, Daniel S, Hurlow A (2016) What determines duration of palliative care before death for patients with advanced disease? A retrospective cohort study of community and hospital palliative care provision in a large UK city. BMJ Open 6(12):e012576

15. Lamont EB, Christakis NA (2002) Physician factors in the timing of cancer patient referral to hospice palliative care. Cancer 94(10):2733-2737

16. Jordan RI, Allsop MJ, ElMokhallalati Y et al (2020) Duration of palliative care before death in international routine practice: a systematic review and meta-analysis. BMC Med 18(1):368

17. Chen $\mathrm{CH}$, Kuo SC, Tang ST (2017) Current status of accurate prognostic awareness in advanced/terminally ill cancer patients: Systematic review and meta-regression analysis. Palliat Med 31(5):406-418

18. Tang ST, Wen FH, Hsieh $\mathrm{CH}$ et al (2016) Preferences for Life-Sustaining Treatments and Associations With Accurate Prognostic Awareness and Depressive Symptoms in Terminally III Cancer Patients' Last Year of Life. J Pain Symptom Manage 51(1):41-51 e41

19. Liu LN, Chen CH, Liu TW, Lin YC, Lee SC, Tang ST (2015) Preferences for Aggressive End-of-life Care and Their Determinants Among Taiwanese Terminally III Cancer Patients. Cancer Nurs 38(3):E9-E18

20. Weeks JC, Catalano PJ, Cronin A et al (2012) Patients' expectations about effects of chemotherapy for advanced cancer. N Engl J Med 367(17):1616-1625

21. Weeks JC, Cook EF, O'Day SJ et al (1998) Relationship between cancer patients' predictions of prognosis and their treatment preferences. JAMA 279(21):1709-1714

22. Kao SC, Butow P, Bray V, Clarke SJ, Vardy J (2011) Patient and oncologist estimates of survival in advanced cancer patients. Psychooncology 20(2):213-218

23. Nogler AF (2014) Hoping for the best, preparing for the worst: strategies to promote honesty and prevent medical futility at end-of-life. Dimens Crit Care Nurs 33(1):22-27

24. Emiloju OE, Djibo DAM, Ford JG (2020) Association Between the Timing of Goals-of-Care Discussion and Hospitalization Outcomes in Patients With Metastatic Cancer. Am J Hosp Palliat Care 37(6):433-438

25. Lopez-Acevedo M, Havrilesky LJ, Broadwater $G$ et al (2013) Timing of end-of-life care discussion with performance on end-of-life quality indicators in ovarian cancer. Gynecol Oncol 130(1):156-161

26. Mack JW, Cronin A, Taback N et al (2012) End-of-life care discussions among patients with advanced cancer: a cohort study. Ann Intern Med 156(3):204-210 
27. Narang AK, Wright AA, Nicholas LH (2015) Trends in Advance Care Planning in Patients With Cancer: Results From a National Longitudinal Survey. JAMA Oncol 1(5):601-608

28. Lund S, Richardson A, May C (2015) Barriers to advance care planning at the end of life: an explanatory systematic review of implementation studies. PLoS One 10(2):e0116629

29. Rocque GB, Dionne-Odom JN, Sylvia Huang CH et al (2017) Implementation and Impact of Patient Lay Navigator-Led Advance Care Planning Conversations. J Pain Symptom Manage 53(4):682-692

30. A controlled trial to improve care for seriously ill hospitalized patients (1995) The study to understand prognoses and preferences for outcomes and risks of treatments (SUPPORT). The SUPPORT Principal Investigators. JAMA 274(20):1591-1598

31. Zaros MC, Curtis JR, Silveira MJ, Elmore JG (2013) Opportunity lost: end-of-life discussions in cancer patients who die in the hospital. J Hosp Med 8(6):334-340

32. Marcia L, Ashman ZW, Pillado EB, Kim DY, Plurad DS (2018) Advance Directive and Do-NotResuscitate Status among Advanced Cancer Patients with Acute Care Surgical Consultation. Am Surg 84(10):1565-1569

33. Abedini NC, Hechtman RK, Singh AD et al (2019) Interventions to reduce aggressive care at end of life among patients with cancer: a systematic review. Lancet Oncol 20(11):e627-e636

34. Starr LT, Ulrich CM, Corey KL, Meghani SH (2019) Associations Among End-of-Life Discussions, Health-Care Utilization, and Costs in Persons With Advanced Cancer: A Systematic Review. Am J Hosp Palliat Care 36(10):913-926

35. Schneiter MK, Karlekar MB, Crispens MA, Prescott LS, Brown AJ (2019) The earlier the better: the role of palliative care consultation on aggressive end of life care, hospice utilization, and advance care planning documentation among gynecologic oncology patients. Support Care Cancer 27(5):19271934

36. Wright AA, Keating NL, Ayanian JZ et al (2016) Family Perspectives on Aggressive Cancer Care Near the End of Life. JAMA 315(3):284-292

37. Bercow AS, Nitecki R, Haber $\mathrm{H}$ et al (2021) Palliative care referral patterns and measures of aggressive care at the end of life in patients with cervical cancer. Int J Gynecol Cancer 31(1):66-72

38. Michael N, Beale G, O'Callaghan C et al (2019) Timing of palliative care referral and aggressive cancer care toward the end-of-life in pancreatic cancer: a retrospective, single-center observational study. BMC Palliat Care 18(1):13

39. Maltoni M, Scarpi E, Dall'Agata M et al (2016) Systematic versus on-demand early palliative care: A randomised clinical trial assessing quality of care and treatment aggressiveness near the end of life. Eur J Cancer 69:110-118

40. Bylicki O, Didier M, Riviere F, Margery J, Grassin F, Chouaid C (2019) Lung cancer and end-of-life care: a systematic review and thematic synthesis of aggressive inpatient care. BMJ Support Palliat Care 9(4):413-424

41. Urvay S, Civelek B, Ozaslan E, Surel AA (2021) Chemotherapy at the End of Life. J Palliat Care 36(2):73-77 
42. Garcia-Martin E, Escudero-Vilaplana V, Fox B et al (2021) Aggressiveness of end-of-life cancer care: what happens in clinical practice? Support Care Cancer 29(6):3121-3127

43. Rautakorpi LK, Seyednasrollah F, Makela JM et al (2017) End-of-life chemotherapy use at a Finnish university hospital: a retrospective cohort study. Acta Oncol 56(10):1272-1276

\section{Supplementary Files}

This is a list of supplementary files associated with this preprint. Click to download.

- SupplementaryTable1.docx

- SupplementaryTable2.docx

- SupplementaryTable3.docx

- SupplementaryTable4.docx 